\title{
Apoptotic Study in Graves Disease Treated with Thyroid Arterial Embolization
}

\author{
Wei ZHAO, Bu LANG GAO, Gen FA YI, CANG ZHENG JIN, HuI Ying YANG**, Li JUAN SHEN*, Min TIAN, \\ YONG ZHONG YU, HONG LI** AND DIAN PING SONG**
}

Medical Imaging Center, First Affiliated Hospital, Kunming Medical College

*Pathology Department, First Affiliated Hospital, Kunming Medical College

**Endocrinology Department, First Affiliated Hospital, Kunming Medical College

\begin{abstract}
Objective: To investigate apoptosis in the thyroid of Graves disease (GD) induced by thyroid arterial embolization. Materials and methods: Forty one patients with clinically and laboratorily ascertained GD were treated with thyroid arterial embolization and followed up for 3-54 months following embolization. Prior to embolization and at 1, 3, 6, 12 and 36 months following embolization, thyroid autoimmunue antibodies were tested respectively, including thyroid stimulating antibody (TSAb), thyroglobulin antibody (TGAb) and thyroid microsomal antibody (TMAb). Thyroid biopsy was performed under the guidance of computed tomography for immunohistochemistry examination using semi-quantity analysis. Results: The positive staining of Fas and FasL was mostly in the cytoplasma and cell membrane, the positive expression of Bax was mainly in the cytoplasma, and no positive expression of P53 was detected in the thyroid cells before embolization. After arterial embolziation, the positive cell number and staining degree of these genes were both greater than before embolization. Conclusion: The treatment method of thyroid arterial embolization can effectively enhance the positive expression of pro-apoptotic genes of Fas, FasL, Bax, Bcl-2 and P53 in GD thyroid, thus promoting apoptosis of GD thyroid and helping restore the thyroid size and function to normal conditions.
\end{abstract}

Key words: Graves disease, Arterial embolization, Apoptosis, Thyroid

(Endocrine Journal 56: 201-211, 2009)

GRAVES disease (GD) is an autoimmune disorder of the thyroid characterized by the production of autoantibodies, especially the thyroid-stimulating autoantibody (TSAb) against the thyrotropin receptor leading to receptor activation and subsequent hyperthyroidism [1-4]. Treatment strategies for GD hyperthyroidism include medical therapy with antithyroid drugs, thyroid surgery or radioiodine therapy $[5,6]$. Conservative therapy with antithyroid drug is usually the first choice in some countries and is lasted for a long term from 12 to 18 months [7]. Nonetheless, side effects of drug therapy such as allergic reactions,

Received: August 25, 2008

Accepted: October 31, 2008

Correspondence to: $\mathrm{Bu}$ Lang GAO, Medical Imaging Center, First Affiliated Hospital, Kunming Medical College, 295 Xicang Road, Kunming, Yunnan Province, China agranulocytosis and hepatotoxicity are not devoid and usually necessitate careful monitoring $[8,9]$. Moreover, the relapse rate at drug therapy withdrawal is very high $(50 \%-60 \%)$ and many patients need further treatment $[10,11]$. Some physicians in the United States in particular favor thyroid ablation as the first choice treatment in most instances [10]. However, ablative treatment may also be accompanied by some unwanted side-effects. Thyroid surgery entails perioperative morbidity, postoperative hypothyroidism and hospitalization costs [6], while radioiodine treatment implies subsequent hypothyroidism and the possibility of secondary neoplasia [12]. With the emergence of thyroid arterial embolization in recent years due to considerable progress made in endovascular technology, GD hyperthyroidism can now be managed through thyroid arterial embolization by occluding most of the thyroid vessels for the reduction of thyroid hormone 
secretion, hence restoring the patient to euthyroidism [13-16]. Up to date, clinical experience with this therapy has been minimal, and further researches have to be performed because many questions remain mysterious. Apoptosis, also known as programmed cell death, is a carefully regulated process of cell death that plays an important role in normal development, morphogenesis and immune function. A basal level of apoptosis may help regulate cell turnover and destruction in the normal thyroid, and antiapoptotic mechanisms may promote survival of thyrocytes in GD [17-19]. This study was to investigate the possible role of apoptosis in GD thyroid treated with thyroid arterial embolization.

\section{Materials and Methods}

During the period between November 2001 and December 2006, 41 GD patients (9 males, 32 females) were enrolled in this study. The study protocol was approved by the Institutional Review Board and the Ethics Committee of the First Affiliated Hospital of Kunming Medical College. Inclusion criteria were noncompliance with or having serious side effects to antithyroid drugs, and refusing surgical and radioactive iodine therapies. The patients, with the age range of 14 to 51 years (mean 32.6 years), had GD confirmed clinically and by laboratory studies and had provided signed informed consent before thyroid arterial embolization. All patients had goiter, with grade I in 5 cases, II in 15, and III in 21, classified in accordance with World Health Organization recommendations [20]. Twenty two of the patients had vascular murmurs in the thyroid area. None of the patients had the history of any other autoimmune, endocrinological and infectious diseases or tumor.

Equipments used in this study included an angiography suite of German SIEMENS BICOR PLUS/TOP model (1250 mA), Holland Phillips MX800 4-row spiral CT scanner and US BD FACSCalibur flow cytometer. The reagents used were FT3, FT4 and rT3 solid phase radioimmuneoassay kits (Jiuding Bioengineering Co. Ltd, Tianjin, China), TT3 and TT4 radioimmunity kits (Xiehe Medical Technology Co. Ltd., Tianjin, China), TGAb and TMAb radioimmunoassay kits, radioreceptor assay kits of human blood TSAb autoimmune antibodies, and hTSH radioimmune kits (IRLAND Corporation, US).
Three days before thyroid arterial embolization, a beta-blocker (propranolol, $10 \mathrm{mg}, 3$ times daily) was administered to bring the patients' heart rate under $100 \mathrm{bpm}$. Methimazole (20-40 mg, 3 times daily) or propylthiouracil (PTU, 50-100 mg, 3 times daily) was also administered to control hyperthyroidism. Experienced interventional radiologists performed thyroid arterial embolization using similar techniques (Fig. 1). Detailed embolization protocol and efficacy assessment of thyroid embolization had been described previously [16]. In brief, after right femoral artery was punctured using the Seldinger technique, a sheath was inserted into the artery, and a $6 \mathrm{~F}$ catheter was put through the sheath into bilateral carotid and subclavian arteries for selective angiography of the thyroid gland. Then, embolization of the thyroid gland was performed. The thyroid major blood supply comes from two pairs of vessels: the left and right superior thyroid arteries that arise from the external carotid arteries, and the left and right inferior thyroid arteries originating from the subclavian arteries. After selective thyroid angiography, a $3 \mathrm{~F}$ SP microcatheter (Boston Scientific, Fremont, CA, USA) was employed to catheterize the gland branches for embolization which targeted two to three major supplying arteries. Generally, bilateral superior arteries were embolized in each case using a mixed product of polyvinyl alcohol, papaverine and a nonionic contrast agent (Omnipaque 300, Amershan Health, Shanghai, China) because these two arteries are usually the thyroid major supplying vessels. In patients with moderate to severe goiter, an inferior thyroid artery was embolized additionally to enforce the effect. Since the parathyroids are mainly supplied by the thyroid bilateral inferior arteries, one inferior artery would usually be left unembolized for fear of hypo-function of the parathyroids [15]. During the procedure, special attention was paid to preventing regurgitation of embolic agent to avoid mis-embolization of other arteries.

After embolization, dexamethasone was administered (10 mg, 3 times daily for 3-7 days) to every patient to inhibit the body's immune system and to relieve symptoms of chemical inflammation of the thyroid gland caused by embolization because the embolized thyroid tissue may become necrotic to temporarily release a great deal of the existing hormones into the blood and cause severe reactions. The patient received IV ampicillin for 3-7 days post embolization to avoid bacterial infection. Antithyroid drugs were 

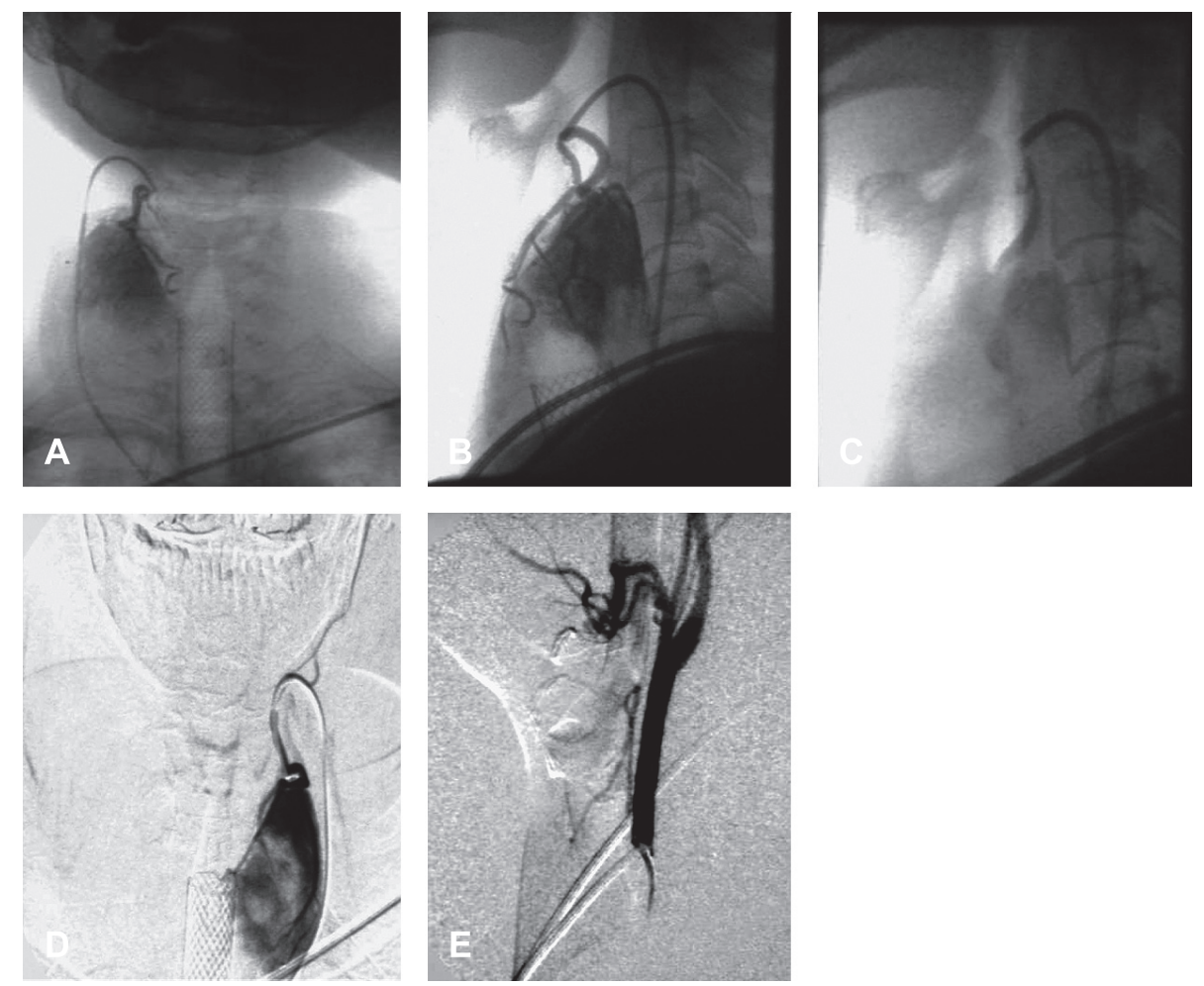

Fig. 1. A 35-year-old woman who had refractory hyperthyroidism was treated with thyroid arterial embolization. A-C. Right superior thyroid artery embolization. A and B. Before embolization, angiography demonstrated abnormal staining of the right lobe. C. After embolization, the abnormal staining had disappeared. D and E. Left thyroid superior arterial embolization. D. Before embolization, abnormal staining of thyroid appeared. E. After embolization, the abnormal staining had disappeared.

continued for 2 weeks after embolization in unchanged doses and gradually reduced or withdrawn based on the thyroid function test.

At 3 days prior to the embolization and at 3 and 7 days, 1, 3, 6, 12, 24 and 36 months following embolization respectively, $5 \mathrm{ml}$ venous blood was harvested in the morning on an empty stomach for the study of thyroid function, including total T4 (TT4), total T3 (TT3), free T4 (FT4), free T3 (FT3), reverse T3 (rT3), thyroid-stimulating hormone (TSH), thyroglobulin antibody (TGAb), thyroid microsome antibody (TMAb), thyroglobulin (TG) and thyroid stimulating antibody (TSAb). Thyroid biopsy with puncture needles under the guidance of computed tomography (CT) was performed on 15 cases before embolization, 2 cases at 7 days, 4 cases at 3 months, 6 cases at 6 months, 7 cases at 1 year and 18 cases at 3 years following thyroid embolization. In 1 case at 3 months, 2 cases at 1 year and 3 cases at 3 years following embolization, no thyroid tissue was present in the pathological sections of the biopsed thyroid tissue. In another two cases at
3 years following embolization, not enough thyroid tissue was obtained for pathological analysis. Therefore, a total of 44 cases had pathological sections for immunohistochemistry examination. After the biopsy was finished, the punctured thyroid was compressed for ten minutes for preventing possible complications. Immunohistochemistry staining was performed on the pathological sections for analysis of expression of the molecules of Fas, FasL, Bcl-2, Bax and p53. The above cases with biopsy were divided into three groups for analysis including 15 cases in the preembolization group, 16 cases in the post-embolization group one at less than 1 year and 13 cases in the postembolization group two at greater than 1 year following embolization.

\section{Statistical analysis}

Statistical analysis was performed with SAS application software package, version 6.12 (SAS Institute Inc., North Carolina State University, NC, USA). 
Continuous data were expressed as mean $(\bar{x} \pm \mathrm{SD})$, or as the median and range if not normally distributed. Various tests were used, including the chi-squared test, ANOVA, Pearson correlation, Fisher's exact test and q-test. A $P$ value $<0.05$ was considered significant, and a $\mathrm{P}$ value $<0.01$ highly significant statistically.

\section{Results}

\section{Complications and Efficacy}

No severe complications occurred immediately after the embolization procedure except slight to moderate neck pain caused by arterial embolization. Vascular murmurs in the anterior neck area disappeared and the enlarged thyroid gland decreased immediately following embolization. Thirty eight patients had been followed up for one to three years following embolization, with 27 being euthyroid (71.1\%), 4 improved $(10.5 \%)$ and 7 recurrent $(18.4 \%)$. Twenty one patients had been followed up over three years, among which 16 were euthyroid (76.2\%) and 5 improved (23.8\%) with reduced dose of antithyroid drugs for mainte- nance. Six more patients with long-term follow-up ( 3 years) were found to be recurrent and were reembolized ( 3 arteries), and thyroid functional test at half a year after embolization showed euthyroid. No side effects occurred during the long-term follow-up.

Positive expression of the molecules of Fas, FasL, Bax, Bcl-2 and 53 on thyrocytes before and after arterial embolziation (Table 1 and 2, and Fig. 2-6)

The expression of Fas, FasL, Bax, Bcl-2 and p53 on thyrocytes before and after arterial embolziation was calculated using semi-quantitative analysis, with the positive signals shown as light yellow to brown particles distributed within the cytoplasma or nuclei. The positive staining of Fas and FasL was mostly restricted to the cytoplasma and cellular membrane. Before arterial embolziation, the positive staining of Fas and FasL in the thyroid cells was very low and sparsely distributed like small patches or dots. After embolization, significantly apparent expression of Fas and FasL was demonstrated within the thyroid tissue like bigger patches, with both the positive cellular number and staining degree greater than before embolization

Table 1. Positive expression of apoptotic genes in GD thyroid

\begin{tabular}{|c|c|c|c|c|c|c|}
\hline \multirow{2}{*}{ Genes } & \multicolumn{2}{|c|}{ PrE group (cases) } & \multicolumn{2}{|c|}{ Group 1 at $\leq 1 \mathrm{y}$ PoE (cases) } & \multicolumn{2}{|c|}{ Group 2 at $>1$ y PoE (cases) } \\
\hline & $-1+$ & $++/+++$ & $-1+$ & $++/+++$ & $-/+$ & $++/+++$ \\
\hline Fas & 9 & 6 & 4 & 12 & 1 & 12 \\
\hline FasL & 12 & 3 & 4 & 12 & 1 & 12 \\
\hline Bax & 7 & 8 & 5 & 11 & 0 & 13 \\
\hline Bcl-2 & 6 & 9 & 7 & 9 & 6 & 7 \\
\hline P53 & 14 & 1 & 6 & 10 & 5 & 8 \\
\hline
\end{tabular}

PrE: pre-embolization, PoE: post-embolization, y: year. As shown in Table 2, a significant or highly siginificant difference existed between Group 1 and PrE Group for Fas $(\mathrm{P}<0.05)$, FasL $(\mathrm{P}<0.01)$ and $\mathrm{P} 53(\mathrm{P}<0.01)$. A highly siginificant difference $(\mathrm{P}<0.01)$ existed between Group 2 and PrE Group for Fas, FasL, Bax and P53. A significant or highly siginificant difference existed between Group 1 and Group 2 for $\mathrm{Bax}(\mathrm{P}<0.05)$ and $\mathrm{P} 53(\mathrm{P}<0.01)$. No significant difference for Bcl-2 between any groups.

Table 2. Significance test of positive apoptotic genes expressed in thyrocytes

\begin{tabular}{|c|c|c|c|c|c|c|c|c|}
\hline \multirow{2}{*}{ Genes } & \multicolumn{2}{|c|}{ General comparison within group } & \multicolumn{2}{|c|}{ Group 1 vs PrE group } & \multicolumn{2}{|c|}{ Group 2 vs PrE group } & \multicolumn{2}{|c|}{ Group 1 vs group 2} \\
\hline & $\mathrm{X}^{2}$ & $\mathrm{P}$ & $\mathrm{X}^{2}$ & $\mathrm{P}$ & $\mathrm{X}^{2}$ & $\mathrm{P}$ & $\mathrm{X}^{2}$ & $\mathrm{P}$ \\
\hline Fas & 9.322 & 0.009 & 3.895 & 0.048 & 8.299 & 0.004 & 1.506 & 0.220 \\
\hline FasL & 18.498 & 0.000 & 10.165 & 0.001 & 15.542 & 0.000 & 1.506 & 0.220 \\
\hline Bax & 7.847 & 0.020 & 0.776 & 0.379 & 1.000 & 0.007 & 4.909 & 0.027 \\
\hline $\mathrm{Bcl}-2$ & 0.838 & 0.658 & 0.819 & 0.366 & 0.108 & 0.743 & 0.588 & 0.715 \\
\hline P53 & 110730 & 0.003 & 9.600 & 0.002 & 9.614 & 0.002 & 1.000 & 0.007 \\
\hline
\end{tabular}

$\mathrm{P}<0.05$ indicates a significant difference while $\mathrm{P}<0.01$ indicates a highly significant difference. 

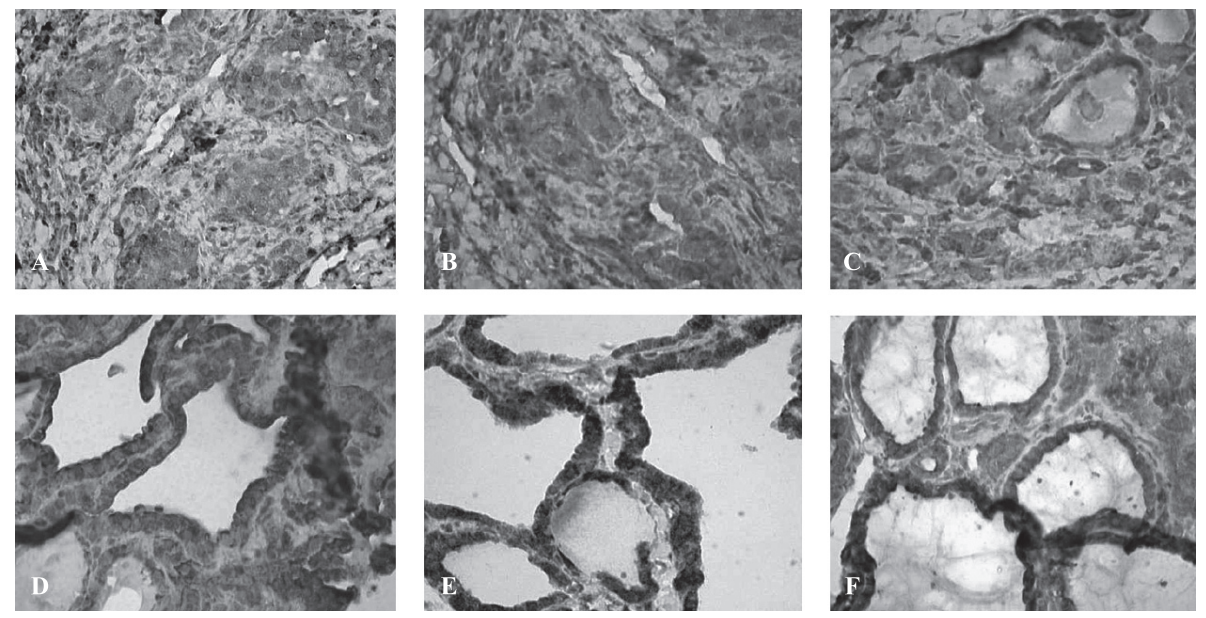

Fig. 2. The expression of Fas increased with time $(\times 400)$. A. Before embolization, the expression of Fas was like small patches within the GD thyroid tissue. B, C \& D. At 7 days (B), 3 months (C) and 6 months (D) following embolization, Fas expression was gradually enhanced. There were some atrophied follicles and some non-specific staining. E \& F. At one year (E) and three years (F), Fas expression greatly increased in both positive cellular number and staining degree, with the staining mainly within the cytoplasma and on the cell membrane and partly in the nuclei $(\times 400)$.
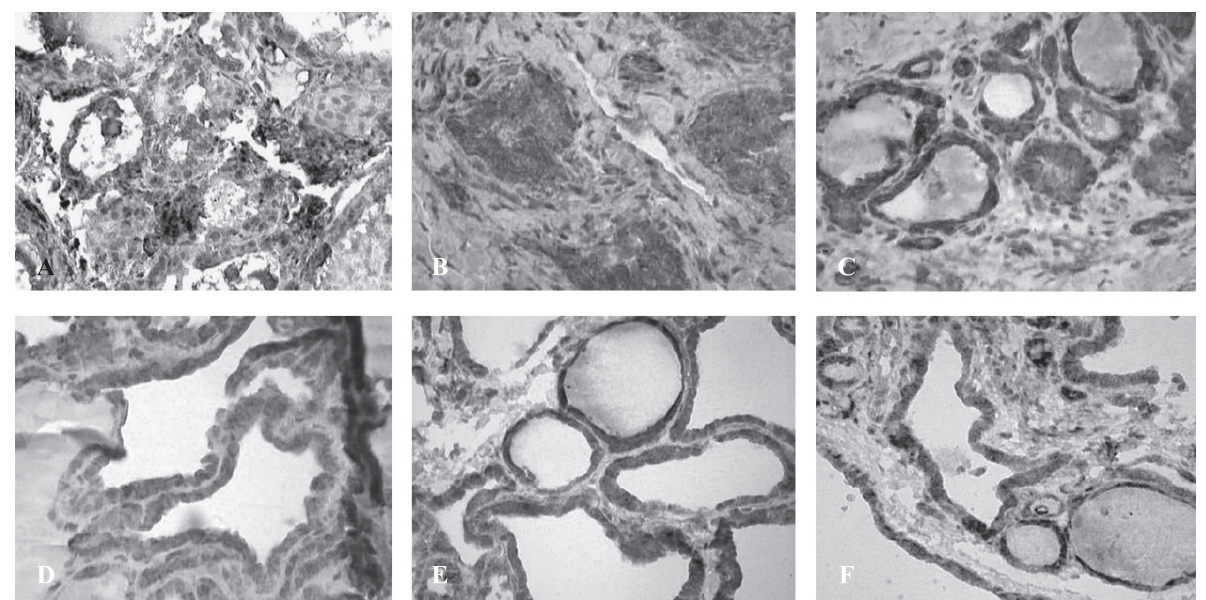

Fig. 3. The expression of FasL increased over time $(\times 400)$. A. Before embolization, FasL was sparsely expressed within the cytoplasma and partly in the nuclei. B, C \& D. At 7 days (B), 3 months (C) and 6 months (D) following embolization, Fas expression was gradually enhanced. There were some atrophied follicles and some non-specific staining. E \& F. At one (E) and three (F) years, FasL expression was greatly enhanced and was mainly expressed within the cytoplasma and on the cellular surface and partly in the nuclei.

( $\mathrm{P}<0.05$, Fig. 2 and 3). The expression of Bax and Bcl-2 was both within the cytoplasma, with no apparent difference in the positive cellular number and degree between pre-embolization group and postembolization group one $(\mathrm{P}>0.05)$, but significant difference between pre-embolization group and postembolization group two in the positive cellular number and degree ( $\mathrm{P}<0.05$, Fig. 4 and 5). P53 was usually negative or distributed like small patches before embo- lization, whereas after embolization, the P53 positive cellular number and staining degree increased with time and were significantly higher than before embolization $(\mathrm{P}<0.05$, Fig. 6$)$.

\section{Changes of serum thyroid hormones and autoantibodies}

The changes of serum thyroid hormones and autoantibodies following embolization were shown in Table 3. 

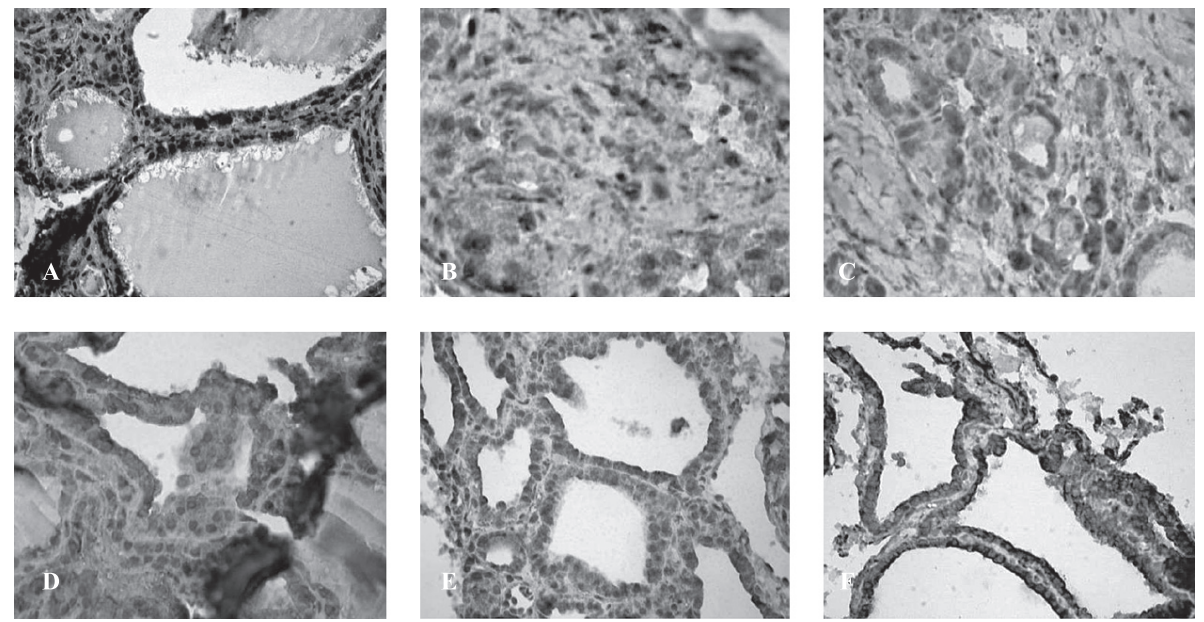

Fig. 4. The expression of Bax was significantly enhanced at more than one year following embolization compared with before embolization $(\times 400)$. A. Before embolization, Bax was sparsely expressed within the cytoplasma and the nuclei of GD thyroid tissue. B, C \& D. At 7 days (B), 3 months (C) and 6 months (D) following embolization, Bax expression was gradually enhanced, but no significant differences existed at less than one year after embolization compared with before embolization. There were some atrophied follicles and some non-specific staining. E. At one (E) and three (F) years, Bax expression was significantly greatly enhanced and was mainly expressed within the cytoplasma and partly in the nuclei.
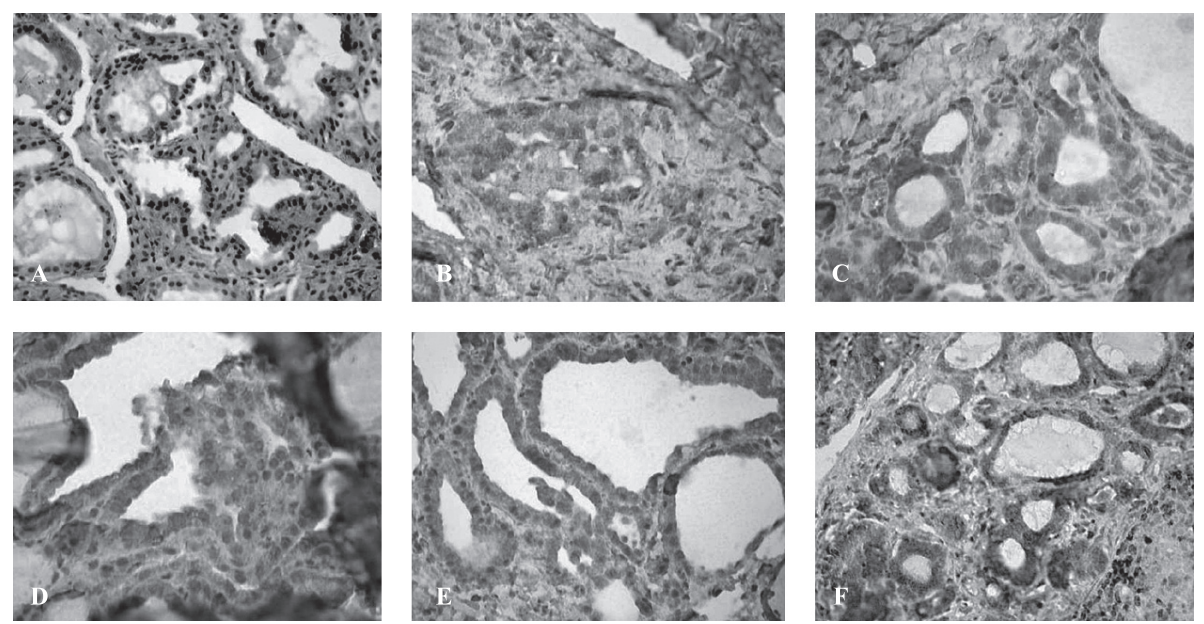

Fig. 5. The expression of Bcl-2 was not significantly different before embolization and at different time points after embolization $(\times 400)$. A. Before embolization, Bcl-2 expression was mainly within the nuclei and partly within the cytoplasma. B, C, D, E \& F. At 7 days (B), 3 months (C), 6 months (D), 1 year (E) and 3 (F) years after embolization, Bcl-2 was sparsely expressed mainly within the cytoplasma but partly within the nuclei.

TT3, TT4, FT3 and FT4 were all lower at over 6 months after than before embolization with a statistical significance. TGAb and TMAb were higher at 3 years after embolization than both before embolization and 6 months after embolization, with a statistical significance. TSAb values were significantly lower at over 6 months following embolization than before embolization, whereas TSH values were significantly higher over 6 months after than before embolization.

\section{Discussion}

Antithyroid drugs, radioiodine and surgery are the three current therapies for GD [21-23]. These treatment modalities are effective in alleviating hyperthyroidism and can result in the inhibition of thyroid hormone synthesis, destruction and removal of thyroid tissue, respectively. However, routine clinical practice reveals that some GD patients may not be controlled 

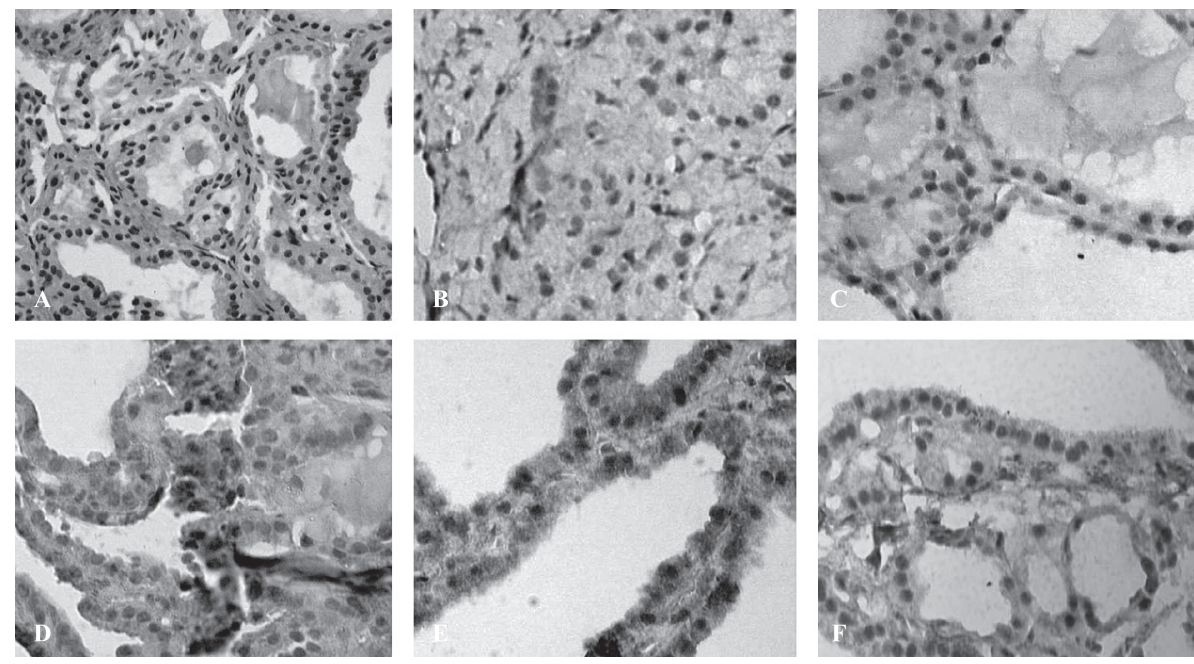

Fig. 6. The positive cellular number and staining degree of p53 increased with time and were significantly higher than before embolization $(\mathrm{P}<0.05)(\times 400)$. A. Before embolization, the expression of $\mathrm{p} 53$ was negative in GD thyroid tissue. B \& $\mathrm{C}$. At 7 days (B) and 3 months (C) following embolization, slight expression of p53 was present in the nuclei. D. At 6 months, the p53 expression in the nuclei was stronger than at 3 months, and furthermore, p53 expression also presented in the cytoplasma. E \& F. At one (E) and three $(F)$ years, the expression of p53 was continuously enhanced compared with at 6 months and was located in the cytoplasma and the nuclei.

Table 3. Changes of the serum thyroid hormones and autoantibodies

\begin{tabular}{|c|c|c|c|c|c|}
\hline & TT3 & TT4 & rT3 & FT3 & FT4 \\
\hline NR & $1.1 \sim 3.4 \mathrm{nmol} / \mathrm{L}$ & $58 \sim 161 \mathrm{nmol} / \mathrm{L}$ & $0.53 \sim 1.15 \mathrm{nmol} / \mathrm{L}$ & $2.3 \sim 7.68 \mathrm{pmol} / \mathrm{L}$ & $10 \sim 25 \mathrm{pmol} / \mathrm{L}$ \\
\hline $\operatorname{PrE}$ & $6.36 \pm 3.15$ & $199.32 \pm 79.54$ & $2.95 \pm 1.65$ & $13.64 \pm 7.63$ & $39.67 \pm 18.35$ \\
\hline $3 \mathrm{~d}$ PoE & $9.81 \pm 5.37 * *$ & $335.9 \pm 108.74 * *$ & $7.20 \pm 3.16^{* *}$ & $23.45 \pm 16.54 * *$ & $48.73 \pm 14.31^{* *}$ \\
\hline 7d PoE & $4.75 \pm 2.51$ & $213.30 \pm 85.06$ & $2.81 \pm 1.85$ & $12.60 \pm 8.78$ & $35.83 \pm 15.79$ \\
\hline $1 \mathrm{~m} \mathrm{PoE}$ & $2.93 \pm 1.24 * *$ & $118.21 \pm 39.45^{* *}$ & $1.34 \pm 0.6^{*}$ & $6.10 \pm 2.80^{*}$ & $23.77 \pm 6.21 *$ \\
\hline $3 \mathrm{~m}$ PoE & $3.25 \pm 1.27^{*}$ & $122.51 \pm 37.76^{*}$ & $1.50 \pm 0.57 *$ & $5.99 \pm 2.11^{*}$ & $22.68 \pm 6.93 *$ \\
\hline $6 \mathrm{~m} \mathrm{PoE}$ & $3.24 \pm 1.16^{*}$ & $148.35 \pm 49.50^{*}$ & $1.76 \pm 0.64$ & $7.24 \pm 3.07 *$ & $29.21 \pm 14.12 *$ \\
\hline 1y PoE & $3.16 \pm 1.14^{*}$ & $143.53 \pm 33.79^{*}$ & $2.33 \pm 1.24$ & $6.79 \pm 3.10^{*}$ & $35.13 \pm 14.35^{*}$ \\
\hline 2y PoE & $2.32 \pm 0.87 *$ & $127.72 \pm 22.54 *$ & $1.23 \pm 0.64$ & $5.71 \pm 1.48^{*}$ & $22.87 \pm 6.56$ \\
\hline \multirow[t]{2}{*}{ 3y PoE } & $2.42 \pm 0.94 *$ & $129.63 \pm 42.42 *$ & $2.52 \pm 1.66$ & $7.21 \pm 3.19^{*}$ & $30.04 \pm 11.2^{*}$ \\
\hline & TSH & TGAb & TMAb & TG & TSAb \\
\hline NR & $0.25 \sim 4 \mathrm{uIU} / \mathrm{ml}$ & $<30 \%$ & $<20 \%$ & $11.45 \sim 20.25 \mathrm{ng} / \mathrm{ml}$ & $<14 \mathrm{U} / \mathrm{L}$ \\
\hline $\operatorname{PrE}$ & $0.11 \pm 0.10$ & $20.59 \pm 16.03$ & $17.91 \pm 13.91$ & $56.25 \pm 49.06$ & $183.1 \pm 176.36$ \\
\hline $3 \mathrm{~d}$ PoE & $0.17 \pm 0.11$ & $8.39 \pm 7.49 *$ & $7.36 \pm 6.77 *$ & $47.92 \pm 45.46$ & $148.65 \pm 17.50$ \\
\hline 7d PoE & $0.32 \pm 0.47$ & $22.96 \pm 14.94$ & $18.64 \pm 12.47$ & $20.14 \pm 7.61$ & $125.6 \pm 110.2$ \\
\hline $1 \mathrm{~m} \mathrm{PoE}$ & $0.08 \pm 0.09$ & $28.82 \pm 17.67$ & $24.14 \pm 15.48$ & $19.99 \pm 9.41$ & $111.2 \pm 107.71$ \\
\hline $3 \mathrm{~m} \mathrm{PoE}$ & $2.00 \pm 3.31^{*}$ & $25.17 \pm 13.59$ & $19.36 \pm 10$ & $11.14 \pm 4.81$ & $96.71 \pm 92.65$ \\
\hline $6 \mathrm{~m} \mathrm{PoE}$ & $2.53 \pm 3.79^{*}$ & $28.14 \pm 23.4$ & $17.96 \pm 14.3$ & $14.2 \pm 5.91$ & $51.07 \pm 37.92 *$ \\
\hline 1y PoE & $0.47 \pm 0.63^{*}$ & $25.55 \pm 17.12$ & $22.74 \pm 15.68$ & $17.5 \pm 5.1$ & $29.63 \pm 8.56^{*}$ \\
\hline 2y PoE & $0.81 \pm 0.85^{*}$ & $35.15 \pm 9.63$ & $30.22 \pm 7.8$ & $22.95 \pm 5.09$ & $7.28 \pm 5.76^{*}$ \\
\hline 3y PoE & $1.04 \pm 1.51^{*}$ & $40.96 \pm 15.82 *$ & $32.70 \pm 12.01 *$ & $36.02 \pm 24.87$ & $25.61 \pm 24.87^{*}$ \\
\hline
\end{tabular}

NR: Normal range, PrE: Pre-embolization, PoE: post-embolization, d: day, m: month, y: year, TT4: total T4; TT3: total T3; FT4: free T4; FT3: free T3; TSH: thyroid-stimulating hormone; $* \mathrm{P}<0.05$ compared to pre-embolization values; $* * \mathrm{P}<0.01$ compared to pre-embolization values. 
with the available therapies due to various reasons like serious allergic reactions to antithyroid agents, uncontrolled hyperthyroidism or other underlying diseases un-amenable to surgical ablation $[13,14,16]$. Some female patients at the reproductive age refuse radioactive iodine treatment because of the possibility of secondary neoplasia and an unfounded albeit belief that it may affect their ability to conceive. These known limitations of the existing therapies for GD underlie our interest in investigating thyroid arterial embolization for such patients. Thyroid arterial embolization has been successfully employed to treat GD hyperthyroidism by some researchers in the world [13, $14,16]$. The procedure is minimally invasive with no need of general anesthesia, and what the doctors have to do is just catheterize the femoral artery under local anesthesia and send a microcatheter endovascularly to two or three major arteries supplying the thyroid gland for delivery of embolic materials such as polyvinyl alcohol particles. The purpose of arterial embolization is to block most of the blood supply to the thyroid gland, resulting in necrosis and later fibrosis of most of the thyroid tissue to substantially reduce secretion of thyroid hormones. This can achieve an effect similar to subtotal surgical thyroidectomy $[13,14,16]$, which is considered the mechanism of thyroid arterial embolization in managing GD hyperthyroidism. Currently limited clinical practices have proved that this technique is a new, effective, minimally invasive and safe method for the treatment of GD patients $[13,14,16]$.

In this study, we investigated the role of apoptosis which is critical in the development and homeostasis of multicellular organisms [24]. An increased rate of apoptosis is involved in the pathogenesis of several degenerative diseases while inhibition of apoptosis has been implicated in autoimmune diseases and carcinogenesis. The percentage of apoptotic thyrocytes in situ is increased in Hashimoto's thyrocytes, but decreased in GD, suggesting the importance of apoptotic cell death of thyrocytes in the regulation of functions and numbers of these cells in autoimmune thyroid diseases $[17,19,25,26]$.

Apoptosis proceeds through the activation of a cascade of effector molecules called caspases, which are responsible for the proteolytic cleavage of nuclear and cytoplasmic substrates and subsequent cellular disassembly [26-28], and apoptosis may be triggered through two major pathways, called the extrinsic and the intrinsic pathway of cell death. The former relies on the recruitment of death receptor family members such as CD95/Fas, TRAILR1, TRAILR2, and TNF$\mathrm{R} 1$. The latter pathway is activated in response to a number of cytotoxic stimuli such as DNA damage, metabolic imbalance, growth factor deprivation, or cell cycle perturbation. These events result in the homodimerization of pro-apoptotic members of the Bcl-2 family such as Bax, Bak, Bim, Bik, or Bid for the recruitment and activation of executioner caspases. Antiapoptotic members of the Bcl-2 family, in particular, Bcl-XL and Bcl-2, prevent apoptosis by counteracting the activity of their pro-apoptotic relatives and thus their expression levels are often indicative of the cell's ability to escape apoptotic death. The Fas receptor and its natural ligand (FasL) are transmembrane proteins, and upon engagement with FasL, cells expressing Fas undergo apoptosis through the activation of an intracellular signaling pathway. Fas-mediated cell death plays a crucial role in immunoregulation and tissue homeostasis, as well as in the immunological clearance of viruses, tumor cells or autoreactive cells [29]. Members of the Bcl-2 family exert their effects by mediating apoptosis rather than cell proliferation, and the ratio of pro-apoptotic to anti-apoptotic proteins in a given cell determines whether it will undergo programmed cell death or not [19]. Bax is a pro-apoptotic protein while $\mathrm{Bcl}-2$ is anti-apoptotic. When one is over-expressed, the effect of the other will be inhibited. P53 is a tumor suppressor gene and its most wellunderstood role is to regulate the transcription of a number of downstream target genes involved in cell cycle arrest, senescence and programmed cell death $[30,31]$. Among the target genes regulated by $\mathrm{p} 53$ are Fas, Bax and Bcl-2. P53 regulates Fas in a p53-dependent manner, up-regulates Bax and down-regulates Bcl-2 [30-32].

In our study, the cellular number and staining degree of positive Fas and FasL were significantly higher than before embolization, which may suggests that thyrocyte apoptosis caused by embolization may overpass thyroid hyperplasia. Although the positive cellular number and degree of pro-apoptotic Bax at one year following embolization were not significantly different from before embolization, those at greater than one year were significantly higher than before embolization $(\mathrm{P}<0.05)$. In contrast, the positive cellular number and staining degree of anti-apoptotic Bcl-2 had no significant difference before and after arterial embolization, namely no increased expression of $\mathrm{Bcl}-2$ 
following embolization. Increased Bax expression implicates enhanced thyrocyte apoptosis. The number and degree of positive p53 cells were significantly higher than before embolization, and through the regulation of its downstream genes, increased p53 expression means promotion of thyroid cell apoptosis [3032]. However, we also detected some expression of mutant p53 in the thyroid following embolization using immunohistochemistry staining in our study, probably because the wide type p53 has a short half life and had quickly turned into the mutant type.

In this study, the expression of some pro-apoptotic genes were promoted to some extent in the GD thyroid before arterial embolization, probably because of the application of antithyroid drugs to control the hyperthyroidism under certain level for the safety of embolization procedure $[2,33]$. Following arterial embolization, the expression of the pro-apoptotic genes was significantly increased, suggesting that the apoptosispromoting role played by the arterial embolization is far greater than the antithyroid drugs. After embolization, dexamethasone was administered to inhibit the body's immune system and to relieve symptoms of chemical inflammation of the thyroid gland caused by embolization. Dexamethasone is a steroid hormone and has the function of anti-inflammation, ananaphylaxis and immunological regulation. It can also influence the reaction of cells to apoptosis, and currently, it has been found that dexamethasone can induce apoptosis of lympholeukocytes, eosinophile granulocytes, osteoblasts and other cells [34-37]. Therefore, dexamethasone may also contribute to some extent to the apoptosis of the thyroid cells after the embolization procedure. However, no great role can be expected from its use.

At three days after embolization (Table 3), the serum thyroid hormones were temporarily greatly increased, probably because the embolized thyroid tissue had become necrotic to release a great deal of the existing hormones stored within the gland. Later, the serum level of thyroid hormone gradually de- creased to normal. This is because embolization caused decreased volume of functioning thyroid tissue, and the synthesis and secretion of hormones was consequently reduced after the stored hormones had been released. The long-term effective rate of thyroid arterial embolization was $80 \%$ (euthyroid plus improved). TGAb and TMAb were significantly higher than before embolization. The existence of these two autoantiboies may reflect the disturbance of the body immune function. TSAb is one of the TSH receptor (TSH-R) autoantibodies (TRAb) in GD patients, and the role of TSAb in the pathogenesis of GD is critical, by activating the receptor and causing hyperthyroidism. At over 6 months after embolization, TSAb was significantly decreased compared with before embolization.

In general, following thyroid arterial embolization, the pro-apoptotic genes expressed in GD thyroid were continuously enhanced, leading to the thyroid cell apoptosis greater than thyroid hyperplasia and consequently reduced hyperfunctional follicles of the thyroid. The regulation process of apoptosis is consistent with the improvement of the body immunity as demonstrated by the decrease of TSAb antibody. Because a therapy directed at the pathogenesis of GD is impossible, current treatment modalities all aim at inhibiting the synthesis and release of thyroid hormones or reducing and destroying the thyroid tissue for secretion of thyroid hormones. However, the improvement of regulation of the whole body immunity should also be stressed at the same time. This study suggests that thyroid arterial embolization can enhance apoptosis of the thyroid cells which may be able to improve the autoimmunity of the thyroid.

\section{Acknowledgements}

This study was sponsored by the Association of Science and Technology of Yunnan Province (2002C0012Z), PR China.

\section{References}

1. Chen CR, Pichurin P, Nagayama Y, Latrofa F, Rapoport B, McLachlan SM (2003) The thyrotropin receptor autoantigen in Graves disease is the culprit as well as the victim. J Clin Invest 111: 1897-1904.
2. Mitsiades N, Poulaki V, Mitsiades CS, Koutras DA, Chrousos GP (2001) Apoptosis induced by FasL and TRAIL/Apo2L in the pathogenesis of thyroid diseases. Trends Endocrinol Metab 12: 384-390. 
3. Prabhakar BS, Bahn RS, Smith TJ (2003) Current perspective on the pathogenesis of Graves' disease and ophthalmopathy. Endocr Rev 24: 802-835.

4. Weetman AP (2003) Grave's disease 1835-2002. Horm Res 59 Suppl 1: 114-118.

5. Cappelli C, Gandossi E, Castellano M, Pizzocaro C, Agosti B, Delbarba A, Pirola I, De Martino E, Rosei EA (2007) Prognostic value of thyrotropin receptor antibodies (TRAb) in Graves' disease: a 120 months prospective study. Endocr J 54: 713-720.

6. Okamoto T, Iihara M, Obara T (2000) Management of hyperthyroidism due to Graves' and nodular diseases. World J Surg 24: 957-961.

7. Feldt-Rasmussen U, Glinoer D, Orgiazzi J (1993) Reassessment of antithyroid drug therapy of Graves' disease. Annu Rev Med 44: 323-334.

8. Toft AD, Weetman AP (1998) Screening for agranulocytosis in patients treated with antithyroid drugs. Clin Endocrinol (Oxf) 49: 271.

9. Weetman AP (2000) Graves' disease. $N$ Engl J Med 343: 1236-1248.

10. Abraham P, Avenell A, Park CM, Watson WA, Bevan JS (2005) A systematic review of drug therapy for Graves' hyperthyroidism. Eur J Endocrinol 153: 489498.

11. Izumi, Y Takeoka, K Amino, N (2005) Usefulness of the 2nd generation assay for anti-TSH receptor antibodies to differentiate relapse of Graves' thyrotoxicosis from development of painless thyroiditis after antithyroid drug treatment for Graves' disease. Endocr $J$ 52: 493-497.

12. Levy EG (1997) Treatment of Graves' disease: the American way. Baillieres Clin Endocrinol Metab 11: 585-595.

13. Galkin EV, Grakov BS, Protopopov AV (1994) [First clinical experience of radio-endovascular functional thyroidectomy in the treatment of diffuse toxic goiter]. Vestn Rentgenol Radiol: 29-35.

14. Xiao H, Zhuang W, Wang S, Yu B, Chen G, Zhou M, Wong NC (2002) Arterial embolization: a novel approach to thyroid ablative therapy for Graves' disease. $J$ Clin Endocrinol Metab 87: 3583-3589.

15. Zhao W, Gao BL, Jin CZ, Yi GF, Yang HY, Li H, Song DP, Hu JH, Jiang YN (2008) Long-Term Immunological Study in Graves' Disease Treated with Thyroid Arterial Embolization. J Clin Immunol.

16. Zhao W, Gao BL, Yang HY, Li H, Song DP, Xiang ST, Shen J (2007) Thyroid arterial embolization to treat Graves' disease. Acta Radiol 48: 186-192.

17. Ai J, Leonhardt JM, Heymann WR (2003) Autoimmune thyroid diseases: etiology, pathogenesis, and dermatologic manifestations. J Am Acad Dermatol 48: 641-659; quiz 660-642.

18. Borgerson KL, Bretz JD, Baker JR Jr (1999) The role of Fas-mediated apoptosis in thyroid autoimmune disease. Autoimmunity 30: 251-264.

19. Phelps E, Wu P, Bretz J, Baker JR, Jr (2000) Thyroid cell apoptosis. A new understanding of thyroid autoimmunity. Endocrinol Metab Clin North Am 29: 375388, viii.

20. Trowbridge FL, Matovinovic J, McLaren GD, Nichaman MZ (1975) Iodine and goiter in children. Pediatrics 56: 82-90.

21. Dworkin HJ, Meier DA, Kaplan M (1995) Advances in the management of patients with thyroid disease. Semin Nucl Med 25: 205-220.

22. Lazarus JH (1995) Guidelines for the use of radioiodine in the management of hyperthyroidism: a summary. Prepared by the Radioiodine Audit Subcommittee of the Royal College of Physicians Committee on Diabetes and Endocrinology, and the Research Unit of the Royal College of Physicians. J R Coll Physicians Lond 29: 464-469.

23. Singer PA, Cooper DS, Levy EG, Ladenson PW, Braverman LE, Daniels G, Greenspan FS, McDougall IR, Nikolai TF (1995) Treatment guidelines for patients with hyperthyroidism and hypothyroidism. Standards of Care Committee, American Thyroid Association. Jama 273: 808-812.

24. Nagata S (1997) Apoptosis by death factor. Cell 88: 355-365.

25. Stassi G, De Maria R (2002) Autoimmune thyroid disease: new models of cell death in autoimmunity. Nat Rev Immunol 2: 195-204.

26. Todaro M, Zeuner A, Stassi G (2004) Role of apoptosis in autoimmunity. J Clin Immunol 24: 1-11.

27. Green D, Kroemer G (1998) The central executioners of apoptosis: caspases or mitochondria? Trends Cell Biol 8: 267-271.

28. Green DR, Reed JC (1998) Mitochondria and apoptosis. Science 281: 1309-1312.

29. Sera N, Kawakami A, Nakashima T, Nakamura H, Imaizumi M, Koji T, Abe Y, Usa T, Tominaga T, Ejima E, Ashizawa K, Yokoyama N, Ishikawa N, Ito K, Eguchi K (2001) Fas/FasL mediated apoptosis of thyrocytes in Graves' disease. Clin Exp Immunol 124: 197-207.

30. Faniello MC, Di Sanzo M, Quaresima B, Baudi F, Di Caro V, Cuda G, Morrone G, Del Sal G, Spinelli G, Venuta S, Costanzo F (2008) p53-Mediated downregulation of $\mathrm{H}$ ferritin promoter transcriptional efficiency via NF-Y. Int J Biochem Cell Biol 40: 2110-2119.

31. Sax JK, El-Deiry WS (2003) p53 downstream targets and chemosensitivity. Cell Death Differ 10: 413-417.

32. Miyashita T, Reed JC (1995) Tumor suppressor p53 is a direct transcriptional activator of the human bax gene. Cell 80: 293-299.

33. Mitsiades N, Poulaki V, Tseleni-Balafouta S, Chrousos GP, Koutras DA (2000) Fas ligand expression in thyroid follicular cells from patients with thionamide- 
treated Graves' disease. Thyroid 10: 527-532.

34. Gorman AM, Hirt UA, Orrenius S, Ceccatelli S (2000) Dexamethasone pre-treatment interferes with apoptotic death in glioma cells. Neuroscience 96: 417-425.

35. Meagher LC, Cousin JM, Seckl JR, Haslett C (1996) Opposing effects of glucocorticoids on the rate of apoptosis in neutrophilic and eosinophilic granulocytes. J Immunol 156: 4422-4428.

36. Silvestrini G, Ballanti P, Patacchioli FR, Mocetti P, Di
Grezia R, Wedard BM, Angelucci L, Bonucci E (2000) Evaluation of apoptosis and the glucocorticoid receptor in the cartilage growth plate and metaphyseal bone cells of rats after high-dose treatment with corticosterone. Bone 26: 33-42.

37. Steighner RJ, Povirk LF (1990) Bleomycin-induced DNA lesions at mutational hot spots: implications for the mechanism of double-strand cleavage. Proc Natl Acad Sci USA 87: 8350-8354. 